\title{
Hyperlipidemia Diet Reduces Superoxide Dismutase Inhibition Rate in the Brain Organ of Rattus norvegicus
}

\author{
Muhammad Luthfi Adnan, Miranti Dewi Pramaningtyas*, Dini Islamiana, Hilmi Ardian \\ Sudarto \\ Department of Physiology, Faculty of Medicine, Universitas Islam Indonesia, Sleman, Indonesia
}

\begin{abstract}
DATA OF ARTICLE:
Received: 31 Jan 2020

Reviewed: 21 July 2020

Revised: 16 Nov 2021

Accepted: 09 Dec 2021

CORRESPONDENCE:

miranti.dewi@uii.ac.id

DOI:

10.18196/mmjkk.v21i2.8167

Abstract: Quail (Coturnix coturnix japonica L.) egg yolk is one of the high-fat foods which can trigger hyperlipidemia. The condition of hyperlipidemia can have an oxidative stress effect on the brain. Superoxide dismutase (SOD) is a natural antioxidant that acts as a defense mechanism against oxidative stress. The inhibition rate of SOD decreases when oxidative stress occurs. This study aims to determine the effect of quail egg yolk on the SOD inhibition rate of brain organs on a rat. This study used male Wistar rats aged 2-3 months with 200-300 grams of weight. The rats were divided into two groups. Each group was fed with ad libitum for two weeks. The A groups as control continued ad libitum consumption, and the B group was given additional quail egg yolk $5 \mathrm{ml} /$ $200 \mathrm{~g} \mathrm{BW}$ for 2 weeks. At the end of the study, the rats were terminated. The brain organs were examined for SOD inhibition rate with spectrophotometry. The mean

TYPE OF ARTICLE: Research SOD inhibition rate in the A and B groups was $74.14 \% \pm 6.16$ and $24.14 \% \pm 5.65$, respectively. The independent t-test showed significant differences in SOD inhibition rate between groups $(\mathrm{p}<0.001)$. Furthermore, quail egg yolk significantly reduced the SOD inhibition rate in the brain organ of the rat.
\end{abstract}

Keywords: Hyperlipidemia Diet; Quail Egg Yolk; SOD Inhibition; Rattus norvegicus

\section{INTRODUCTION}

Hyperlipidemia is a condition when cholesterol or triglyceride levels increases beyond the standard (Total Cholesterol $\geq 240 \mathrm{mg} / \mathrm{dL}$ and triglycerides $\geq 200 \mathrm{mg} / \mathrm{dL}$ ). Hyperlipidemia is a risk factor that can increase cardiovascular disease in the future. Some cardiovascular disease conditions can occur in atherosclerosis, coronary heart disease, and myocardial infarction. In addition to increasing the risk of cardiovascular disease, hyperlipidemia also increases the risk of organ damage that can cause several diseases such as stroke.

Genetic factors or secondary causes can cause hyperlipidemia. Some secondary causes of hyperlipidemia include metabolic disorders such as hypothyroidism, obesity, type 2 diabetes mellitus, and high fat and caloric diets such as sweet drinks, alcohol, and foods containing lots of cholesterol. ${ }^{1}$ One of the foods that have a high cholesterol content is quail (Coturnix coturnix japonica $L$ ) egg yolk which reaches 844 $\mathrm{mg} / \mathrm{dL} .^{2}$

Several previous studies showed that hyperlipidemia could trigger oxidative stress. Metabolic disorders cause oxidative stress at the cellular function level of the mitochondrial part. The condition can produce reactive oxygen species (ROS). Under normal conditions, ROS levels have a minimal effect on cell damage by balancing the body's antioxidant defense system. ${ }^{3}$ Reactive Oxygen Species (ROS) levels are controlled by antioxidants in the body in the form of superoxide dismutase (SOD). Superoxide dismutase in the body limits ROS's potential toxicity and prevents extensive molecular damage. ${ }^{4}$

Oxidative stress can affect the brain. Oxidative stress in the brain can cause chronic diseases such as stroke and Alzheimer's disease 3,5 . The disease can occur as oxidative stress plays an important role in the inflammatory process that results in atheroma plaque that can cause a stroke. ${ }^{3}$

Superoxide dismutase is an endogenous antioxidant that acts as a brain's defense mechanism. ${ }^{6} \mathrm{It}$ is important to understand the activity of SOD in the brain when oxidative stress occurs due to the vital function 
of the brain as a central nervous system. Oxidative stress in this research was achieved by creating a hyperlipidemic condition. The induction material used to create this condition is quail egg yolk which has the highest cholesterol level compared to other eggs. This study aims to determine how quail egg yolk administration affects superoxide dismutase inhibition rate in hyperlipidemic rat brain organs.

\section{MATERIALS AND METHOD}

\section{Research Design}

This study used an experimental laboratory design with male Rattus norvegicus Wistar strain as subjects. The independent variable in this study was a high-fat diet in the form of quail egg yolk. The dependent variable was the SOD inhibition rate in the brain organ. The research group was divided into two groups: A group as a control group and $B$ group as an intervention group which received additional quail egg yolk. Both groups were fed ad libitum for two weeks. As a control group, Group A continued to be fed ad libitum until one month. The intervention group was given a high-fat diet for two weeks with a dose of $5 \mathrm{ml} /$ 200gr Bw. The high-fat diet intervention was done by the sonde method. This study has received ethical clearance approval from the Faculty of Medicine Ethics at Universitas Gajah Mada with the number $\mathrm{KE} / \mathrm{FK} / 0803 / \mathrm{EC} / 2019$.

\section{Time and Place}

The research was conducted at the Physiology Laboratory of the Faculty of Medicine, Universitas Islam Indonesia and the Pusat Antar Universitas (PAU) Universitas Gajah Mada from April to June 2019. The samples were 24 rats. The characteristics of the sample used were: male Wistar rats aged 2-3 months, weighing 200- 300 grams and no physical abnormalities.

\section{Trials on Experimental Rats}

There were 24 rats divided into two groups. The 24 rats were allowed to undergo an acclimatization process for seven days. Rats in A group were fed rat pellets ad libitum with a 40 grams/day/rat volume and given $50 \mathrm{ml}$ of distilled water/day/rat. Rat and aquades feed were replaced every day in the morning. The $B$ group was induced to be hypercholesterolemia by inducing quail egg yolk 5ml / 200 gr WB for 2 weeks using sonde. Indicators of hypercholesterolemia included an increase in lipid profile in the rat; more than $130 \mathrm{mg} /$ $\mathrm{dL}$ of LDL levels, less than $40 \mathrm{mg} / \mathrm{dL}$ of HDL, more than $150 \mathrm{mg} / \mathrm{dL}$ of triglycerides, and more than $200 \mathrm{mg} /$ $\mathrm{dL}$ of total cholesterol. Collecting blood samples was conducted at the end of the intervention. A sampling of rat blood from Plexus retroorbitalis as much as $3-5 \mathrm{~mL}$ was previously anesthetized using ketamine and xylazine as much as $0.1-0.33 \mathrm{~mL}$ injected intramuscularly. The serum was transferred into a new tube, and lipid profile levels were checked and monitored, including total cholesterol, triglycerides, LDL, and HDL. The rat terminated after collecting the blood sample, and the brain organ was collected to check the SOD inhibition rate. To maintain the quality, rat brain organs were wrapped in aluminum foil paper and stored in a freezer at $-4^{\circ} \mathrm{C}$. The organs were then taken to the UGM Inter-University Center (PAU) to examine the brain organs' MDA levels and SOD inhibition rate.

\section{Superoxide Dismutase Inhibition Rate Testing}

Analysis of SOD inhibition rate was carried out by means of $0.06 \mathrm{~mL}$ brain supernatant reacted with a mixture consisting of $2.70 \mathrm{~mL} 50 \mathrm{mM}$ sodium carbonate buffer containing 0.01mM EDTA (pH 10), $0.06 \mathrm{mM}$ xanthine $10 \mathrm{Mm}, 0.03 \mathrm{mM}$ Bovine serum albumin (BSA), and $0.5 \%$ of $0.03 \mathrm{mM}$ Nitro blue tetrazolium chloride (NBT) $2.5 \mathrm{mM}$. The addition of xanthine oxidase (0.04 units) was then carried out. After 30 minutes, the absorbance value was measured at a wavelength of $560 \mathrm{~nm}$ using a spectrophotometer. SOD levels were calculated according to the following formula: SOD inhibition rate $(\%)=[1-A / B] \times 100 \%$, where $A=A b s o r b a n c e$ of sample solution and $B=$ Absorbance of control solution. ${ }^{7}$ After the SOD examination was complete, an Independent-Sample T-Test was performed to unreveal the effectivity of quail egg yolk in reducing SOD inhibition rate. The data was analyzed by software SPSS version 21.

\section{RESULTS}

After the intervention was completed, the experimental animals and brain organs were terminated. The data obtained were then analyzed descriptively using statistical software to find out the mean and range of each group from the measurement results obtained, as shown in Table 1. 
Table. 1 The Average SOD Inhibition Rate of Research Groups

\begin{tabular}{lll}
\hline Research Group & Average SOD inhibition rate (\%) & P value \\
\hline Control group & $74.13 \pm 6.16$ & 0.001 \\
Intervention Group & $24.13 \pm 5.65$ & \\
\hline
\end{tabular}

The mean SOD inhibition rate in the control group was $74.13 \% \pm 6.16$, while, in the intervention group, it was $24.13 \% \pm 5.65$. The Independent-Sample T-Test showed significant differences in the SOD inhibition rate between the two groups $(p<0.001)$. This means that the intervention group has a significantly lower SOD inhibition rate than the control group.

The average results from examining rat lipid levels in the control group and intervention group are shown in Figure 2. It appears that there was an increase in triglyceride and LDL levels, and a decrease in $\mathrm{HDL}$ in the intervention group compared to the control group.

Table 2. Total Cholesterol, Triglyceride, HDL, and LDL Level of Each Group

\begin{tabular}{lllll}
\multicolumn{5}{c}{ Table 2. Total Cholesterol, Triglyceride, HDL, and LDL Level of Each Group } \\
\hline Research Group & $\begin{array}{l}\text { Total } \\
(\mathrm{mg} / \mathrm{dL})\end{array}$ & $\begin{array}{l}\text { Triglyceride } \\
(\mathrm{mg} / \mathrm{dL})\end{array}$ & $\begin{array}{l}\text { HDL } \\
(\mathrm{mg} / \mathrm{dL})\end{array}$ & LDL (mg/dL) \\
\hline Control Group & 88.05 & 72.54 & 89.41 & 26.25 \\
Intervention Group & 189.61 & 120.14 & 24.39 & 89.85 \\
\hline
\end{tabular}

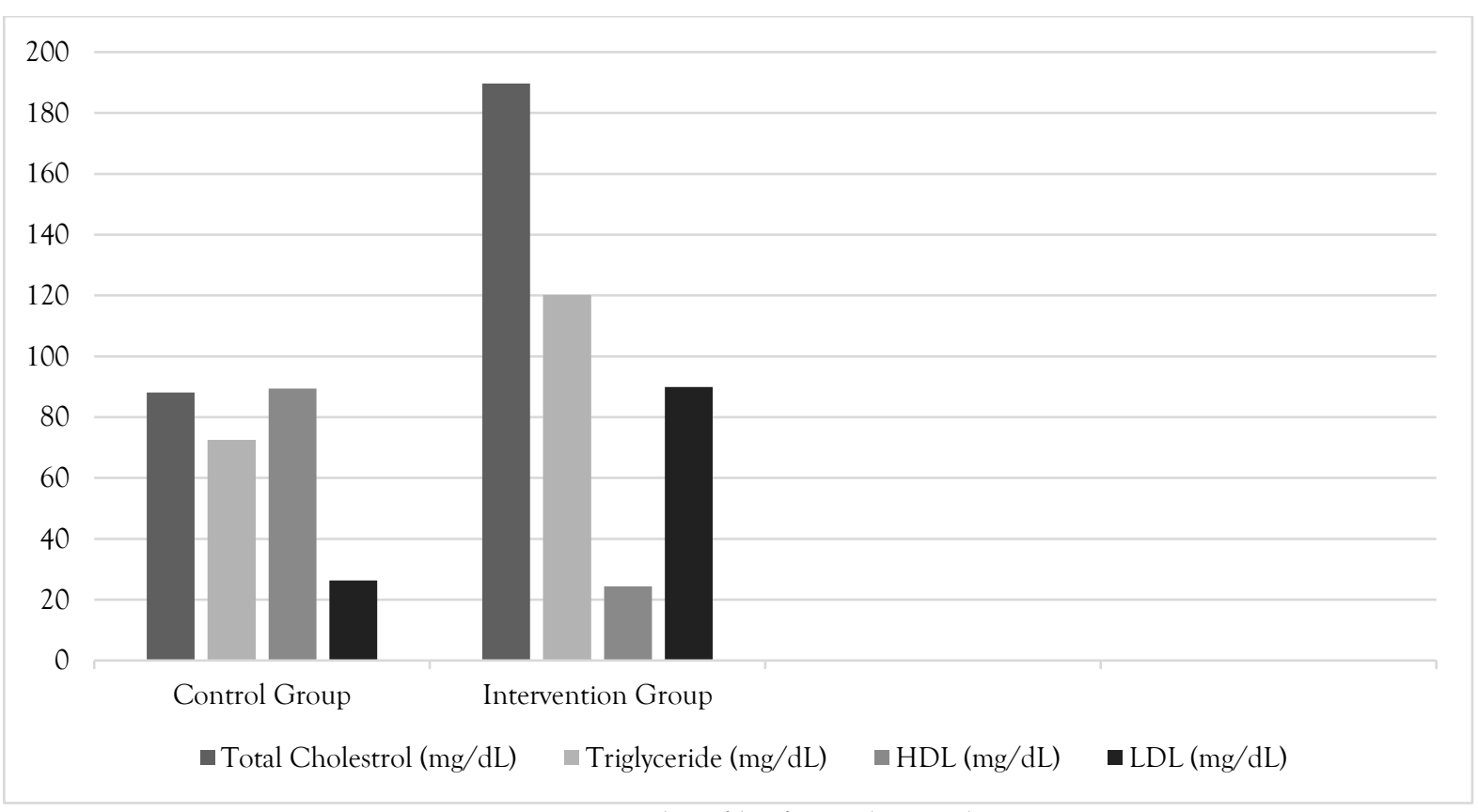

Figure 2. Lipid Profile of Tested Animal

\section{DISCUSSION}

The level of SOD inhibition in the rat with egg yolk group was lower than in the rat group without egg yolk. Superoxide dismutase is a natural antioxidant in cells that acts as an antidote to free cells damage. Hyperlipidemia induced by quail egg yolk affects decreasing the level of SOD inhibition. Low SOD conditions indicate the process of cell damage due to oxidative stress caused by free radicals. ${ }^{8}$

Superoxide dismutase inhibition rate works against free radicals as catalysts in the breakdown of superoxide $(\mathrm{O})$ anions into oxygen and hydrogen peroxide. ${ }^{9}$ There are three types of SOD families based on their ability to bond with metals, namely SOD Cu/ ZN, which can bind with copper and zinc; SOD Fe/ Mn, which can bind to iron and manganese iron and SOD Ni, which can bind to nickel. SOD locations that work in cells are SOD1 in the cytoplasm, SOD2 located in the mitochondria and SOD 3 located in extracellular. ${ }^{8,10}$

Superoxide dismutase is the most important antioxidant defense in the body. It acts as an antioxidant enzyme with an anti-inflammatory agent and prevents the transformation of cells into precancerous cells. Decreased levels of SOD make cells vulnerable to diseases related to oxidative stress. ${ }^{11}$ 
This condition shows the impact of decreasing SOD level on a person's susceptibility to degenerative diseases such as Alzheimer's disease, myocardial infarction and various types of cancer. ${ }^{12-14}$

There is high malondialdehyde (MDA) content in the quail egg yolk, which results from lipid peroxidation due to the unavailability of oxygen during the embryonic development stage. High MDA content is caused by the transfer of yolk containing unsaturated fat to the embryo during the embryogenesis period of poultry eggs. During the incubation process, the embryo does not get enough oxygen, resulting in MDA accumulation in the yolk. ${ }^{15}$ Finally, the MDA content becomes accumulated in egg yolk if consumed, which is associated with an increase in cholesterol and can trigger various diseases in the body. ${ }^{16}$

Egg yolk content rich in cholesterol can result in hyperlipidemic conditions. ${ }^{17}$ The high consumption of egg yolks in cholesterol which has high levels of MDA, can interfere with lipid metabolism at the cellular level. At a further level, the accumulation of MDA from free radical reactions is cytotoxic and mutagenic. Malondialdehyde exposure is harmful to the cell structure of membranes, proteins, lipoproteins and deoxyribonucleic acid (DNA), which can cause degenerative and chronic diseases. ${ }^{18}$ This study used quail egg yolk to create hyperlipidemia in the rat. The egg yolk was used in this study as it has a high cholesterol content. The hyperlipidemia condition is considered the originator of oxidative stress, which causes an imbalance in oxidants and antioxidants. Superoxide dismutase is the main antioxidant that will increase oxidative stress's initial stages.

The lipid profile in this study showed that total cholesterol, triglycerides and LDL in the intervention rat group were higher than in the control group. HDL levels in the intervention rat group were lower than in the control group. The results of rat lipid profile examination showed a correlation between hyperlipidemic conditions and decreased SOD inhibition rate in the intervention group. In this study, the SOD inhibition rate in the group that received quail egg yolk was lower than in the control group. It is an effect of the oxidative stress conditions that occur in hyperlipidemia. In hyperlipidemia, there is an increase in reactive oxygen species that are free radicals and become oxidants. An increase will naturally follow these free radicals in SOD levels that are antioxidants. When hyperlipidemia continues, the levels of oxidants become greatly increased, resulting in an imbalance between oxidants and antioxidants. Superoxide dismutase inhibition rate is then reduced. The effect of quail (Coturnix coturnix japonica L.) egg yolk has been extensively investigated for its higher fat and cholesterol content compared to the content of other poultry eggs. Based on research conducted by Ukachukwu et al. (2017), the cholesterol and lipid content in quail egg yolk is more than that of chicken egg yolk $(6.99 \mathrm{mg} / \mathrm{dl}$ and $4.0 \mathrm{mg} / \mathrm{dl})$. However, when examined as a whole, the highest cholesterol and lipid content is in whole chicken eggs compared to whole quail eggs $(239.30 \mathrm{mg} / \mathrm{dl}$ and $35.40 \mathrm{mg} / \mathrm{dl}){ }^{19}$

Furthermore, when consumed in normal amounts, cholesterol positively affects the body. Cholesterol can be useful as a precursor of steroid hormones, synthesis of bile acids for digestion, ingredients for the formation of cell components, and tissue regeneration. In pregnant women, it is important for the production of breast milk. ${ }^{20}$ However, when consumed excessively, high cholesterol and lipid content can increase the risk of developing cardiovascular disease and type 2 diabetes mellitus. ${ }^{17}$

Consumption of foods that contain lots of fat and cholesterol can trigger the condition of hyperlipidemia. Hyperlipidemia is a risk factor for cardiovascular disease (CVD). Cardiovascular Disease occurs due to high levels of low-density lipoprotein cholesterol (LDL-C), which causes damage to the endothelial cells of blood vessels. Damaged blood vessels will trigger the formation of thrombus which then triggers atherosclerosis and increases the occurrence of myocardial infarction. ${ }^{21}$

Hyperlipidemia condition for the body will then trigger the formation of free radicals. It also can lead to changes in physical properties in the cell membrane, resulting in the formation of reactive oxygen specimens (ROS) from mitochondria in the NADPH oxidase reaction. The ROS can react with lipid membranes and produce radical peroxide lipids. The increase in lipid peroxide by free radicals is a consequence of the increased oxidative stress condition due to hyperlipidemia. ${ }^{22}$

In addition, the most important form of body compensation when there are high levels of free radicals in the body is by producing antioxidants. The body's first-line antioxidants to be produced are superoxide dismutase (SOD) and catalase and glutathione peroxidase (GSH). However, a state of hyperlipidemia can cause an increase in ROS levels which makes it difficult for the body to compensate so that it affects decreasing antioxidant activity, one of which is SOD. ${ }^{23}$

Decreased levels of SOD in the body's organs indicate serious damage in organ cells. ${ }^{24}$ Moreover, the decreased level of SOD in brain organs indicate damaged brain cell due to high free radicals, which are caused by oxidative stress in hyperlipidemic conditions. ${ }^{5}$ Apart from the formation of free radicals, the condition of hyperlipidemia can cause deadly effects on neuronal cells and cause inflammatory reactions that interfere with endothelial cells in blood vessels. Vascular disorders due to hyperlipidemia can increase pressure on the 


\section{mutiara medika}

blood-brain barrier (BBB), resulting in brain edema. Brain edema can later develop further into an ischemic stroke. ${ }^{25}$

In addition to causing ischemic stroke in the brain, a decrease in SOD inhibition rate can pose a risk of dementia and Alzheimer's disease. The disease is such a neurodegenerative disease due to decreased nerve function. Decreased SOD inhibition rate easily causes nerve damage in nerve cells due to damage to nerve synapses by oxidative stress. In addition to causing damage to synapses, oxidative stress also produces $\beta$-amyloid $(A \beta)$, which plays an important role in the onset of Alzheimer's disease. ${ }^{26,27}$

\section{CONCLUSION}

It can be concluded that the condition of hyperlipidemia induced by quail yolk cause a decrease in the SOD inhibition rate of brain organs.

\section{ACKNOWLEDGEMENT}

The authors thank Reza Ishak Estiko for editing this manuscript.

\section{CONFLICT OF INTEREST}

There is no conflict of interest between all of the authors.

\section{REFERENCES}

1. Nelson RH. Hyperlipidemia as a Risk Factor for Cardiovascular Disease Robert. Prim Care. 2013;40(1):195211. https://doi.org/10.1016/j.pop.2012.11.003

2. Sentosa M, Saraswati TR, Tana Si. Kadar High Density Lipoprotein ( HDL) Telur Puyuh Jepang (Coturnix japonica L.) setelah Pemberian Tepung Kunyit ( Curcuma longa L .) pada Pakan. Buletin Anatomi dan Fisiologi. 2017;2(1):67-71. https://doi.org/10.14710/baf.2.1.2017.67-71

3. Yang R-L, Shi Y-H, Hao G, Li W, Le G-W. Increasing Oxidative Stress with Progressive Hyperlipidemia in Human: Relation between Malondialdehyde and Atherogenic Index. Journal of Clinical Biochemistry and Nutrition. 2008;43(3):154-8. https://doi.org/10.3164/jcbn.2008044

4. Wang Y, Branicky R, Noë A, Hekimi S. Superoxide dismutases: Dual roles in controlling ROS damage and regulating ROS signaling. Journal of Cell Biology. 2018;217(6):1915-28. https://doi.org/10.1083/jcb.201708007

5. Dias IHK, Polidori MC, Griffiths HR. Hypercholesterolaemia-induced oxidative stress at the blood-brain barrier. Biochemical Society Transactions. 2014;42(4):1001-5. https://doi.org/10.1042/BST20140164

6. Puglia CD, Loeb GA. Influence of rat brain superoxide dismutase inhibition by diethyl-dithiocarbamate upon the rate of development of central nervous system oxygen toxicity. Toxicol Appl Pharmacol. 1984;75:25864. https://doi.org/10.1016/0041-008X(84)90208-4

7. Weydert C, Cullen J. Measurement of superoxide dismutase, catalase, and glutathione peroxidase in cultured cells and tissue. Nature Protocols. 2010;5(1):51-66. https://doi.org/10.1038/nprot.2009.197

8. Lobo V, Patil A, Phatak A, Chandra N. Free radicals, antioxidants and functional foods: Impact on human health. Pharmacognosy Reviews. 2010;4(8):118-26. https://doi.org/10.4103/0973-7847.70902

9. Fukai T, Ushio-Fukai M. Superoxide dismutases: Role in redox signaling, vascular function, and diseases. Antioxidants and Redox Signaling. 2011;15(6):1583-606. https://doi.org/10.1089/ars.2011.3999

10. Indo HP, Hsiu-Chuan Yen, Ikuo Nakanishi, Ken-ichiro Matsumoto MT, Nagano Y, Matsui H, Gusev O, Cornette R, et al. A mitochondrial superoxide theory for oxidative stress diseases and aging. Journal of Clinical Biochemistry and Nutrition. 2015;56(1):49-56. https://doi.org/10.3164/jcbn.14-42

11. Younus H. Therapeutic potentials of superoxide dismutase. International journal of health sciences. 2018;12(3):88-93.

12. Seshadri G, Sy JC, Brown M, Dikalov S, Yang SC, Murthy N, et al. The delivery of superoxide dismutase encapsulated in polyketal microparticles to rat myocardium and protection from myocardial ischemiareperfusion injury. Biomaterials. 2010;31(6):1372-9. https://doi.org/10.1016/i.biomaterials.2009.10.045

13. Murakami K, Murata N, Noda Y, Tahara S, Kaneko T, Kinoshita N, et al. SOD1 (copper/zinc superoxide dismutase) deficiency drives amyloid $\beta$ protein oligomerization and memory loss in mouse model of Alzheimer disease. Journal of Biological Chemistry. 2011;286(52):44557-68. https://doi.org/10.1074/jbc.M111.279208 
14. Robbins D, Zhao Y. Manganese superoxide dismutase in cancer prevention. Antioxidants and Redox Signaling. 2014;20(10):1628-45. https://doi.org/10.1089/ars.2013.5297

15. Tsunekage $\mathrm{T}$, Ricklefs RE. Increased lipid peroxidation occurs during development in Japanese quail (Coturnix japonica) embryos. British Poultry Science. 2015;56(2):262-6. https://doi.org/10.1080/00071668.2014.994592

16. Binder CJ, Papac-Milicevic N, Witztum JL. Innate sensing of oxidation-specific epitopes in health and disease. Nature Reviews Immunology. 2016;16(8):485-97. https://doi.org/10.1038/nri.2016.63

17. Spence JD, Jenkins DJA, Davignon J. Dietary cholesterol and egg yolks: Not for patients at risk of vascular disease. Canadian Journal of Cardiology. 2010;26(9):336-9. https://doi.org/10.1016/s0828-282x(10)70456-6

18. Pizzino G, Irrera N, Cucinotta M, Pallio G, Mannino F, Arcoraci V, et al. Oxidative Stress: Harms and Benefits for Human Health. Oxidative Medicine and Cellular Longevity. 2017;2017. https://doi.org/10.1155/2017/8416763

19. Uzochukwu G, Ozougwu VE., Nicodemus E. A Comparative Study on the Total Cholesterol , Triacylglycerides and Lipid Concentrations of Quail and Chicken Eggs. International Journal of Research in Pharmacy and Biosciences. 2017;4(10):11-6.

20. Purba SL, Saraswati TR, Isdadiyanto S. The effect of organic quail egg supplementation on the blood lipid profile of white rat (Rattus Norvegicus L.) during the lactation period. Journal of Physics: Conference Series. 2018;1025(1). https://doi.org/10.1088/1742-6596/1025/1/012077

21. Mingpakanee R, Chaisitthichai C, Wichitamporn N, Sappittayakorn P, Phongphanwatana S. The Effect of Quail Egg and Hen Egg Consumption on Low-Density Lipoprotein Oxidation and Small Dense Low-Density Lipoprotein. Journal of Health Science and Medical Research. 2019;37(2):109-20. https://doi.org/10.31584/jhsmr.201946

22. Singh UN, Kumar S, Dhakal S. Study of Oxidative Stress in Hypercholesterolemia. International Journal of Contemporary Medical Research. 2017;26(5):1204-7.

23. Ighodaro OM, Akinloye OA. First line defence antioxidants-superoxide dismutase (SOD), catalase (CAT) and glutathione peroxidase (GPX): Their fundamental role in the entire antioxidant defence grid. Alexandria Journal of Medicine. 2018;54(4):287-93. https://doi.org/10.1016/j.ajme.2017.09.001

24. Wei LF, Zhang HM, Wang S Sen, Jing JJ, Zheng ZC, Gao JX, et al. Changes of MDA and SOD in brain tissue after secondary brain injury with seawater immersion in rats. Turkish Neurosurgery. 2016;26(3):384-8. https://doi.org/10.5137/1019-5149.JTN.8265-13.1

25. Menet R, Bernard M, ElAli A. Hyperlipidemia in stroke pathobiology and therapy: Insights and perspectives. Frontiers in Physiology. 2018;9(MAY):1-6. https://doi.org/10.3389/fphys.2018.00488

26. Ansari MA, Scheff SW. Oxidative Stress in the Progression of Alzheimer Disease in the Frontal Cortex. Journal of Neuropathology Eु Experimental Neurology. 2010;69(2):155-67. https://doi.org/10.1097/NEN.0b013e3181cb5af4

27. Youssef P, Chami B, Lim J, Middleton T, Sutherland GT, Witting PK. Evidence supporting oxidative stress in a moderately affected area of the brain in Alzheimer's disease. Scientific Reports. 2018;8(1):1-14. https://doi.org/10.1038/s41598-018-29770-3 